\title{
HISTORIOGRAFÍA DE LA EDUCACIÓN FÍSICA EN COLOMBIA
}

Víctor Jairo Chinchilla $\mathbf{G}^{*}$

La historia de la educación física en Colombia se ha escrito de diferentes maneras, sin que se pueda afirmar que en la actualidad es un campo consolidado de investigación. Por el contrario, todo indica que la investigación histórica, en sentido estricto, es incipiente y apenas se despierta el interés por una interpretación desde la perspectiva de las ciencias sociales y, en particular, la ciencia histórica.

Si bien la educación física busca su justificación en la presencia que ha tenido en la historia del hombre desde la edad de las cavernas, afirmando el papel del movimiento y el juego en la humanización y en los ritos de iniciación, y es muy frecuente que en el ideal griego se tenga la explicación de los orígenes y finalidades de la educación del cuerpo, es preciso reconocer que en Colombia no se ha dado un desaff0110 a los estudios históricos en sentido estricto.

Cuando se asume el estudio histórico de la educación física, una de las características más notorias, es el entrecruzamiento de diferentes prácticas, que si bien tienen su propia especificidad, son la base sobre la cual la educación física elabora su acción educativa y cultural, como es el caso del deporte, el juego, el cuerpo, la recreación que en sus inicios constituían un todo en la formación, y en el transcurso de la evolución han conformado campos específicos, incluso con tensiones entre ellos. En este entrecruzamiento participan también las miradas que se hacen desde las perspectivas de la educación, la pedagogía, la antropología y la medicina, que de una u otra forma hacen referencias a la educación física desde su objeto particular de interés.

Por ello en este balance se considera la educación física como un área que integra diferentes prácticas sociales que tienen su realización en la corporalidad del hombre y se transforman de acuerdo con la dinámica de la sociedad, dando respuesta a intereses y transformaciones de la cultura, que las destaca, según el momento, como medios, fines, actividades o instrumentos.

\section{Importancia de los estudios históricos}

Es interesante apreciar en el conjunto de la educación y de la sociedad una actitud contrapuesta, entre el reconocimiento que se hace de la importancia de la educación física y sus funciones en la persona y la cultura, con su poco apoyo y valoración desde el punto de vista de la investigación y reconocimiento de su importancia en los estudios académicos, sociales y culturales. Ello ha traído como consecuencia una escasa atención a problemas del conocimiento histórico de la educación física en la sociedad, y la pérdida de una información útil para comprender procesos actuales de formación de la subjetividad, la socialización y el desarrollo del conocimiento que mantienen las separaciones entre la escuela y la sociedad, entre el cuerno y el alma, entre el juego y la vida.

\footnotetext{
* Investigador de la Universidad Pedagógica Nacional. 
Manifestaciones de la poca atención a la historia de la educación física son el descuido de los archivos en su conservación, mantenimiento, sistematización y uso. Prácticamente están desaparecidos los archivos de la Comisión Nacional de Educación Física que funcionó entre 1925 y 1968, los planes y programas de las instituciones educativas, los textos, programas e informes, los aparatos, elementos y planos de las prácticas educativas y culturales. En una mirada restrictiva, apenas perviven rasgos de memorias de hechos y algunas hazañas de triunfos deportivos. La anécdota se impone sobre la mirada analítica del estudioso de la sociedad y la cultura. Se manifiesta aquí el desprecio por un campo de la experiencia humana, que se da por hecho, pero que se deja allí, como si no fuera necesaria su atención dada su presencia real en la cultura. El cuerno, el movimiento, el juego, el ocio, se viven, disfrutan o sufren pero a la hora de la definición de los temas de interés científico o filosófico, quedan aislados por una especie de recarga de intelectualismo y desprecio de lo práctico y su significación.

En este contexto se han realizado diversos trabajos sobre historia de la educación física que se pueden caracterizar de acuerdo con sus enfoques y métodos de elaboración, en aquellos que se basan en criterios cronológicos, descriptivos y anecdóticos, y que tienen en la evolución de las normas su principal fuente, hasta trabajos que empiezan a conformar un campo de investigación en los cuales se tratan diferentes temas, enfoques e intereses de conocimiento.

Si bien no se puede establecer una categorización muy precisa, sí se aprecia en ellos una evolución conceptual de la educación física correlacionada con un nivel de maduración en la investigación histórica, cuestión que pone en evidencia que los estudios históricos son cada vez más importantes en la interpretación de la sociedad y del papel que desempeña en ella la educación, y en particular la educación física.

No se contemplan aquí trabajos muy parciales sobre historias particulares de deportes, como las dedicadas al fútbol o el ciclismo, pues ellas hacen parte de un interés más particular.

\section{Trabajos iniciales}

En la escritura de la historia de la educación física en Colombia se ubica un conjunto de trabajos descriptivos, anecdóticos, estructurados en un ordenamiento cronológico y articulados a la expedición de la legislación, que proporcionan una información útil pero no problematizan con modelos teóricos, ni relaciones entre la sociedad y la cultura y el hecho mismo de la educación física.

Uno de los primero trabajos fue elaborado por el profesor uruguayo Raúl Blanco en su texto sobre la historia universal de la educación física ${ }^{86}$, en donde en el capítulo referido a Colombia, manifiesta las dificultades para obtener información sobre la educación física y los juegos recreacionales. hace el recuento de la Ley 80 de 1925 y su reglamentación en los años subsiguientes, describe las funciones de la Comisión Nacional de Educación Física y las recomendaciones del Congreso de Profesores de Segunda Enseñanza realizado en noviembre de 1943, que solicitan financiación y nombramiento de profesores. Menciona además, la solicitud de la Asociación Nacional de Profesores de Educación Física para la

\footnotetext{
${ }^{86}$ Raúl Blanco, Educación física un panorama a su historia, Editora Adroher, Montevideo, 1948. p., 168-184. 
reorganización del Instituto Nacional de Educación Física y la organización propuesta por el gobierno para el Plan Nacional de esta actividad. No ubicó el profesor Blanco trabajos como los de Jorge Bejarano o Miguel Jiménez López, que le hubiesen proporcionado una información valiosa sobre la importancia fundamental que se dio a la educación física en las primeras cuatro décadas del siglo $X X$ en los procesos de modernización en estrategias de control del tiempo libre, la dinamización de la escuela activa, el fortalecimiento de la raza y la organización del deporte.

En el año de 1961 el profesor Ernesto Vidales, en su obra Nos dejó el tren escribe algunos capítulos en relación con la evolución de la políticas deportivas, la burocratización y el comportamiento de los dirigentes deportivos, de los políticos y de los profesores de educación física a quienes corresponde la labor "sagrada" de velar por el deporte y el deportista ${ }^{87}$.

Basado en la experiencia directa como profesor y dirigente, muestra de manera irónica la desarticulación entre las exigencias del crecimiento del deporte y el provincialismo e ignorancia de quienes deben dirigirlo; señala los vicios de la organización deportiva y los contrasta con el espíritu de sacrificio del deportista. Destaca el papel del deportista para la sociedad y para la grandeza de la patria y efectúa un análisis de las intenciones de la legislación deportiva y la forma contradictoria e interesada de su aplicación. También se detiene en el estado de la educación física y de la formación de profesores a quienes reclama su función docente y social como conocedores científicos de una actividad que requiere compromiso y dedicación en relación con las necesidades del país.

En 1986, con motivo de la celebración de los cincuenta años del Instituto Nacional de Educación Física, se publicó un texto escrito por Alberto Gómez Moreno y Alberto Parra, quienes hacen un recuento titulado Cincuenta años de historia de la educación física en Colombia como profesión ${ }^{88}$ sobre acontecimientos como la fundación del Instituto Nacional de Educación Física (INEF) y los diferentes traslados hasta su incorporación a la Universidad Pedagógica Nacional; algunas realizaciones de carácter profesional como el primero y segundo Congresos Colombianos de Educación Física, la realización del Cuarto Congreso Panamericano de Educación Física en 1964 y la creación de Coldeportes en 1968. En el trabajo se incluye una reseña biográfica de personalidades de la educación física y el deporte en el país como Gilma Wills, Alberto Nariño Cheyne, José Francisco Socarrás, Gabriel Anzola Gómez y otros personajes a quienes se reconoce su gestión en la fundación y consolidación profesional de la educación física.

El texto narra algunas realizaciones de la educación física a través de sus profesionales, en un ordenamiento cronológico de los acontecimientos sin ahondar en el análisis interno ni las relaciones de contexto. Toma como fuentes las actas de fundación, la legislación, algunos planes de estudio y reseñas de personajes, que se colocan como testimonios y constituyen una importante base de fuentes primarias.

\footnotetext{
${ }^{87}$ Ernesto Vidales, Nos dejó el tren, Editorial Kelly, Bogotá, 1961.

88 Albedo Gómez Moreno y Albedo Parra Parra, Cincuenta años de historia de la educación física como profesión, Universidad Central, Bogotá, 1986. 
Un año después, Ángel Humberto Vaca realiza una compilación de la legislación sobre educación física desde del decreto de Instrucción Pública de 1870, hasta el decreto 2845 de 1984 y algunas de sus disposiciones reglamentarias, titulado Historia de la educación fí?vica a través de sus normas editado por la Universidad Central en $1987^{89}$.

Sigue un estricto orden cronológico y se refiere a los aspectos pertinentes a la educación física en el marco de la legislación educativa general. Destaca como momentos claves en la conformación de la educación física colombiana, el decreto general de instrucción pública de 1870, que incluye la educación física en los principios y objetivos de la instrucción pública y como asignatura escolar; el decreto 491 de 1903 que la define como uno de los componentes de la educación junto a la educación intelectual, moral y cívica; la Ley 80 de 1925 que institucionaliza la organización estatal y social de la educación física; el decreto 1518 de junio de 1936 que dio creación al Instituto Nacional de Educación Física; el decreto 2743 de 1968 que establece la creación de Coldeportes y el decreto 2845 de 1984 que reorganiza el deporte, la educación física y la recreación.

El trabajo de compilación de Vaca, aporta para la investigación histórica una fuente organizada sobre la legislación y sus temas, la evolución de las normas y los personajes que participaron en su elaboración, así como la conformación de las instituciones estatales y sociales como los organismos que agrupan el deporte asociado. La compilación tiene una finalidad pedagógica que busca un mejoramiento de la educación física actual, tal como lo expresa el autor:

Comprender la historia de los juegos y el deporte y entender las decisiones de los dirigentes deportivos y de los gobernantes de la educación y de la educación física es indagar para preveer y poder actuar con éxito en el futuro... De ahí que normas como el decreto Orgánico de 1870 y la Ley 80 de 1925 primeras disposiciones que fijaron claras políticas o investigar los decretos que regulan la actividad deportiva, o comparar los planes y programas de la educación física escolar es ejercitación conveniente para determinar rumbos de acción, tendencias, programas, planes, realizaciones, estancamientos y progresos que a la largo de estos años ha tenido la educación física ${ }^{90}$.

Contiene además otras decisiones sobre educación física, como por ejemplo, normas generales sobre planes de estudio, intensidad horaria, contratación de profesores y programas de extensión extraescolar.

Sin embargo, no expone ninguna posición crítica sobre la aplicación de esta legislación y los factores que influenciaron los cambios legislativos y de programas. Es importante tener en cuenta que la expedición de una abundante legislación no siempre se relaciona con efectos prácticos en la cultura, y que muchas veces la expedición de una norma obedece a situaciones muy coyunturales, que en el transcurso del tiempo quedan sin aplicación efectiva y sin los avances progresivos que muchas veces se percibe en la evolución de las normas.

El mismo autor realiza una compilación tanto de legislación como de documentos oficiales, actas, planes y programas, que titula Historia del Alma Mater de la Educación Física

\footnotetext{
${ }^{89}$ Ángel Humberto Vaca, Historia de la educación física colombiana a través de sus normas, Universidad Central, Bogotá, 1987.

${ }^{90}$ Ibíd.,p. 1. 
Colombiana ${ }^{91}$ dedicada a la evolución de la facultad de Educación Física de la Universidad Pedagógica Nacional, desde la fundación del Instituto Nacional de Educación Física, INEF, en el año de 1936; primero como dependencia directa del Ministerio de Educación Nacional y posteriormente de la Universidad, de donde fue expulsado para pasar a la Escuela Normal Superior. Cuando esta última se cierra en el gobierno de Laureano Gómez funciona la Escuela Nacional de Educación Física Femenina y la Escuela Nacional de Educación Física Masculina. Posteriormente éstas se integran en la Escuela Nacional de Educación Física que dos años más tarde se incorpora a la Universidad Pedagógica Femenina, para constituir la Universidad Pedagógica Nacional.

La Historia del Alma Mater de la Educación Física Colombiana permite apreciar las motivaciones políticas, los personajes y las tendencias conceptuales iniciales de la formación de profesores de educación física en Colombia, a través de la asesoría de la Misión chilena, influenciada a su vez por la escuela gimnástica sueca, que se basaba en fundamentos fisiológicos y anatómicos para la educación del cuerno y del movimiento.

Otro trabajo difundido en el medio deportivo y recreativo es el realizado por el periodista Alberto Galvis Ramírez, quien con motivo del centenario del periódico El Espectador, realizó una serie de artículos sobre la historia de la educación física y el deporte desde la legislación de Francisco de Paula Santander hasta el año del centenario del periódico (1987). Posteriormente recoge estos artículos en un libro que denominó Laureles (1988), actualizado en 1996 con el título Oro plata y bronce: una aproximación a la historia del deporte colombiano $^{92}$ en ocasión de los XV Juegos Deportivos Nacionales realizados en la ciudad de Bucaramanga.

El texto comprende desde las actividades físicas de los indígenas que sufrieron el dominio español, hasta los acontecimientos deportivos de la actualidad. Si bien en la primera parte se aprecia una referencia cultural y social, a medida que se avanza en su lectura, el recuento se limita a los acontecimientos deportivos, y en especial, a narrar las hazañas de los campeones y la organización deportiva y de los grandes eventos. Entre los temas destacados por Galvis están la inclusión de la educación física en el sistema escolar, las primeras organizaciones deportivas, el inicio de las principales modalidades del deporte como el fútbol, el ciclismo, el atletismo y el baloncesto, la organización del Comité Olímpico Colombiano y los Juegos Bolivarianos para celebrar los 400 años de Bogotá en el año de 1938, la realización de los VI Juegos Panamericanos en 1971 y la participación de Colombia en Juegos Olímpicos y otros eventos internacionales.

Galvis plantea las relaciones del deporte con el ambiente político y social de cada uno de los siete períodos en que divide su trabajo. Al establecer la relación entre deporte y sociedad, escribe que

con excepción del criollísimo tejo, legado de nuestros aborígenes, que empezó a jugarse desde tiempos inmemoriales por sus inventores, aunque sólo se organizó a medida que surgieron las asociaciones nacionales, la clase adinerada fue la primera en hacer deporte en Colombia, especialmente por las posibilidades de viajar y conocer el mundo. Pero poco a poco, contrario a lo que sucedió con la guabina, que nació en el pueblo y penetró en los elegantes salones de la

\footnotetext{
91 Ángel Humberto Vaca, Historia del Alma Mater de la Educación Física Colombiana, Bogotá, UPN, 1994.

92 Albedo Galvis Ramírez, Oro, plata y bronce: una aproximación a la historia del deporte colombiano, publicación con motivo de los XV Juegos Nacionales, Bucaramanga, 1996. 
sociedad, el deporte abrió la puerta de las grandes mansiones, de los colegios burgueses y de los clubes sociales, para salir de ellos, popularizarse y alcanzar su actual dimensión.

\section{Nuevos temas y enfoques}

En la última década se ha tomado con mayor rigor el trabajo de investigación histórica de la educación física, cuyos primeros esbozos se aprecian en las tesis de grado y de postgrado a través de un tratamiento metodológico y conceptual que busca dar cuenta de la diversidad de temas de interés actual como los referidos a la mujer, al tiempo libre, el cuerpo, las relaciones políticas y culturales, la vida cotidiana, el deporte y la política, el juego y las relaciones con lo pedagógico y lo social.

Una de las características de estos trabajos es la búsqueda e interpretación de fuentes desde un punto de vista teórico de la ciencia histórica, a partir del cual se elabora la narración. Exige esta perspectiva un mayor cuidado metodológico y rigor en las narraciones, que proporciona a la educación física un avance respecto a las realizaciones anteriores y una perspectiva de desarrollo de su conocimiento en el proceso educativo y cultural.

Entre los nuevos temas se destacan las tesis de grado de Patricia Quesada y Néstor Alonso Sánchez, La educación física una historia por construir, de la Universidad del Valle; Luis Ignacio Martínez, Surgimiento del deporte y el tiempo libre en Bogotá 1895-192093 Astríd Bibiana Rodríguez, Educación física y mujer entre 1930 y $1950^{94}$; Aproximación a una historia de la sexualidad de la Universidad Pedagógica Nacional y Luis Alfonso Garzón, Apuntes para la historia de una confusión: educación física-deporte, 1997.

En La educación física en Colombia: una historia por construir ${ }^{95}$ elaborada por Patricia Quesada y Néstor Alonso Sánchez, del Departamento de Educación Física de la Universidad del Valle, se realiza la propuesta de investigar la historía de la educación física a partir de las tesis expuestas por Olga Lucía Zuluaga en la "Historia de las prácticas pedagógicas". Se parte "de la preocupación que existe en los educadores físicos de hoy, por las dificultades que presenta un saber desvinculado de los problemas nacionales, de los conocimientos producidos en otros campos del conocimiento; de la cultura". En busca de una alternativa se asume un enfoque conceptual que parte de la necesidad de reivindicación del cuerpo por la educación física, fundamentado en la experiencia desarrollada en el Seminario del Cuerno realizado en la Universidad del Valle en el año de 1987, en el cual se hace una lectura de Foucault; y en los planteamientos del Tercer Congreso Colombiano de Educación Física organizado en Cartagena en 1988 que plantea la apertura social y cultural de la educación física. Desde las tesis foucoltianas del control y el disciplinamiento sobre la población, se intenta hacer una interpretación de la Ley 80 de 1925 y del decreto 2743 con el cual se creó Coldeportes en 1968, como dispositivos de control del Estado sobre el cuerpo. Este trabajo deja abierta una vía para abordar el problema expuesto desde procesos investigativos más pacientes y meticulosos.

\footnotetext{
93 Luis Ignacio Martínez, Surgimiento del tiempo libre y el deporte en Bogotá 1890-1920. Tesis de grado. Universidad Pedagógica Nacional. Bogotá, 1997.

${ }_{94}$ Astrid Bibiana Rodríguez, Educación física y mujer 1930-1950. Aproximación a una historia de la sexualidad. Tesis de grado. Universidad Pedagógica Nacional, Bogotá, 1997.

${ }^{95}$ Patricia Quesada y Néstor Alonso Sánchez, La educación física en Colombia. Una historia por construir. Tesis de grado. Universidad del Valle. Cali, 1991.
} 
La tesis, Surgimiento del deporte y el tiempo libre en Bogotá 1895-1920,elaborada por el estudiante Luis Ignacio Martínez con un enfoque histórico social, presenta las condiciones sociales y la transformación urbana dentro de la cual fue necesaria la organización del tiempo libre, en cuyo marco tomaron fuerza y se popularizaron los deportes, que antes eran exclusividad de las élites. Analiza la ciudad de Bogotá a finales del siglo XIX y comienzos del $\mathrm{XX}$, caracterizando las actividades de ocio y recreación, el posterior incremento de la población por las migraciones campesinas y los inicios de la industrialización, marco en el cual se hace necesario la organización de actividades recreativas y deportivas, para ocupar sanamente el tiempo libre de los trabajadores y sus familias. Distingue la diferenciación social de las élites y el pueblo manifestada a través de las actividades deportivas, y el papel realizado por las instituciones educativas, en particular los colegios religiosos, en la divulgación del deporte. Se destaca en esta investigación una ampliación en la búsqueda de fuentes que desbordan el campo específico de la educación física para indagar en documentos sociales, culturales y económicos.

La tesis de Astrid Bibiana Rodríguez titulada Educación física y mujer en el período 19301950. Aproximación a una historia de la sexualidad asume como tema la discriminación social y educativa de la mujer, las características que se le dieron a la educación física femenina, sesgada por concepciones y prejuicios sobre la sexualidad de la mujer. Esta discriminación se inicia, según la autora, dando una característica de debilidad a las capacidades de la mujer y asignando a la educación una función para la preparación de su papel de madre abnegada y dependiente tanto del esposo como de los hijos. Trata el tema de la eugenesia, la higiene y las normas de control del cuerpo de la mujer. Por ello la educación física femenina debe realizarse de manera independiente de los varones y efectuar ejercicios adecuados a su naturaleza biológica y psicológica y a la atención de normas sociales de conducta. Realiza un seguimiento de fuentes de prensa, y materiales sobre el tema de influencia en la políticas de salud, higiene y educación en la primera mitad del siglo $X X$ y se detiene en las formas de prejuicios e imágenes sobre el cuerpo y la sexualidad femenina.

En el año de 1996 se presentó un trabajo en la especialización de pedagogía y didáctica de la educación física de la Universidad Pedagógica Nacional, titulado Horizonte de sentido de la educación física colombiana, realizado por un equipo integrado por Víctor Jairo Chinchilla, Iván Torres, Clara Lourdes Peña, Julia Peña, Farid Salgado y Simón Cruz. Sobre tres ejes de análisis, neoliberalismo, educación-escuela y educación física, hace un recorrido sobre la evolución de la educación física en el marco del pensamiento político del liberalismo, según el cual, el crecimiento del capitalismo que desarrolla la industria y cambia las formas de vida artesanales y rurales hacia formas de vida urbana y de tecnificación, produce la necesidad de adiestramiento de habilidades y destrezas, de aprendizajes de reglas de comportamiento y de organización del espacio y el tiempo que presentan las condiciones propicias para el surgimiento y consolidación de la educación física en las instituciones educativas y en el conjunto de la sociedad, hasta llegar a la etapa del neoliberalismo, dentro del cual se intensifica el individualismo y la comercialización del deporte y del uso del cuerpo. Este planteamiento sirve de base para pensar en una pedagogía de la educación física que busque alternativas al modelo dominante, o en nombre de la globalización y mundialización, se constituya en instrumento de difusión y fortalecimiento del modelo neoliberal.

Si bien, se aprecia en él una perspectiva social y política amplia que aclara las relaciones entre modelos políticos y educativos, y abre el camino para un historia política de la Digitalizado por RED ACADEMICA 
educación física, adolece de una consulta de fuentes primarias, que deja muchos planteamientos sin la suficiente demostración.

Oro trabajo que corresponde a este grupo de investigaciones es el realizado por Luis Alfonso Garzón, como tesis de maestría, Apuntes para la historia de una confusión:educación física-deporte ${ }^{96}$. Aborda diferentes paradigmas de la educación física, entre las cuales señala el castrense, el organicista, psicomotriz y el paradigma cognitivo motriz. Fundamenta estos paradigmas en documentación de las corrientes pedagógicas y gimnásticas, y en las teorías filosóficas y antropológicas sobre el control del cuerpo en particular del origen europeo. En la segunda parte plantea diferentes momentos de la evolución histórica de la educación física en Colombia y la influencia en ella de los paradigmas europeos. Concluye con la necesidad de una educación física alternativa, que no sea excluyente y defina la actividad física como "una acción consciente, objetiva, creadora, práctico material que permita el desarrollo y expansión del ser humano. Provocando cambios en la estructura jerárquico-social, y ayudando a eliminar la concepción de privatización deportiva".

\section{Perspectivas desde lo social y pedagógico}

Desde un punto de vista que se inscribe en la historia social y cultural de la educación, Martha Cecilia Herrera y Carlos Low en "Los intelectuales y el despertar de la modernidad. El caso de la Escuela Normal Superior una historia reciente y olvidada"97 abordan el tema de la Normal Superior y el movimiento intelectual en el proceso de la modernización del país en el periodo histérico de la República Liberal, dentro del cual destacan el lugar asignado a la educación física. A través del estudio institucional se presentan las diferentes influencias del contexto, los intereses científicos y académicos y sus relaciones con lo político y el papel social en el período de la República Liberal y su posterioridad. en particular en la cualificación de la docencia y la formación del maestro. "La Escuela Normal Superior se proyectó hacia un mejoramiento del status del maestro de secundaria y de la universidad, y tuvo mucho que ver con la profesionalización de la docencia y en el mejoramiento de la dignidad del maestro"98. Además permitió una influencia de la intelectualidad en la universidad y otras instituciones del país.

Respecto a la educación física el trabajo relata la organización del Instituto Nacional de Educación Física en la Escuela Normal Superior, sus pénsumes y sus egresados. Además plantea que "la educación física comienza a ser considerada como un saber que posee un estatuto teórico propio, cuyo objeto de estudio es la reflexión en torno al movimiento, al desarrollo del cuerpo y su papel en la formación integral del individuo".

\section{En la Normal}

se configura un discurso sobre el cuerno que se aleja de la concepción moralista difundida por la pedagogía católica, según la cual el cuerno era instrumento de pecado; el nuevo discurso se apoyaba en las ideas de la Escuela Activa y colocaba el énfasis en la higiene, la alimentación y el ejercicio físico, dando cabida a la sistematización y valoración de la enseñanza de la

\footnotetext{
96 Luis Alfonso Garzón, Apuntes para la historia de una confusión: educación física-deporte. Tesis de grado, Maestría en Historia de la Educación y la Pedagogía, Universidad Pedagógica Nacional, 1997.

${ }_{97}$ Martha Cecilia Herrera y Carlos Low, Los intelectuales y el despertar cultural del siglo. El caso de la Escuela Normal Superior una historia reciente y olvidada. Universidad Pedagógica Nacional, Bogotá, 1994.

${ }^{9}$ Ibíd. p. 127. 
educación física y la promoción e impulso del deporte en los establecimientos educativos del país ${ }^{99}$.

En este trabajo se efectúa un amplio tratamiento de fuentes institucionales y se utilizan las historias de vida de los personajes representativos de la Institución y de seguimiento a la mayoría de egresados. Con ello se busca un amplio conjunto de bases para construir el discurso histórico.

Martha Cecilia Herrera en su texto sobre Modernización y Escuela Nueva en Colombia 1914-1951 (1999 ) señala la incorporación de la educación física en los planes de estudio como uno de los elementos de introducción de procesos de modernización. Plantea el cambio de las concepciones mecánicas de cuerpo en el siglo XIX al planteamiento de una gimnasia científica, desde la cual se regulan los movimientos hacia el fortalecimiento de la raza y el vigor del cuerpo. Destaca los objetivos de la creación del Instituto Nacional de Educación Física en el gobierno de Alfonso López Pumarejo y la importancia que tuvo la práctica de la educación física en el período en el cual fue Ministro de Educación Jorge Eliécer Gaitán para quien "la práctica del deporte y el ejercicio físico proporcionaban al Estado seres que han aprendido la importancia de ajustar los ademanes de cada cual en un esquema de conjunto" 100

La investigación Mirar la infancia: pedagogía, moral y modernidad en Colombia, 19031946, de Javier Sáenz Obregón. Óscar Saldarriaga y Armando Ospina ${ }^{101}$ desarrolla un intenso tratamiento de fuentes sobre el papel de la pedagogía en la modernidad, sustentado en el cambio de concepción del niño de sujeto pasivo a sujeto activo, y los procesos de apropiación en el cual se dieron. Enfrenta la polémica sobre lo tradicional y lo moderno y demuestra el proceso de constitución del sujeto, de la institución escolar y del saber pedagógico.

El discurso modernista en Colombia, entre 1903 y 1934, atraviesa el conjunto de los saberes, los conceptos y los objetos de los discursos sobre la escuela, el maestro, los métodos de enseñanza, los fines de la educación y las estrategias de formación. Lo moderno era la ciencia y su método, los saberes experimentales y aplicados — prácticos_ los métodos inductivos y experimentales en la ciencia y en la enseñanza, la actividad, la conducta, lo medible, lo material, lo visible, lo útil, lo actual, lo individual, lo natural; en fin, la unidad entre lo físico, lo moral y lo intelectual ${ }^{102}$.

En este contexto se efectúa una amplia referencia a la educación física y su papel en la escuela activa través de varios tipos de relación: La educación física y su influencia sobre el! individuo a partir de la unidad entre lo físico, lo intelectual y lo moral, la salud y la higiene; la educación física y la regeneración del pueblo, desde la preocupación por la raza y la moralización; la educación física en la concepción del niño activo como medio y como método; la educación física y la adecuación de las funciones de la escuela a las nuevas exigencias de la modernidad como el uso del tiempo libre y la participación de la mujer, y el

\footnotetext{
99 Ibíd. p. 65.

${ }^{100}$ Martha Cecilia Herrera, Modernización y Escuela Nueva en Colombia 1914-1951. Universidad Pedagógica Nacional

101 Javier Sáenz, Óscar Saldarriaga y Armando Ospina, Mirar la infancia: pedagogía, moral y modernidad en Colombia: 1903-1946. Ed. Colciencias, Foro Nal. por Colombia, U. de Antioquia, Bogotá, 1997.

102 Ibíd., Vol.2, p. 8. 
proceso de autonomización de la educación física como un campo de desarrollo de políticas escolares y extraescolares.

Se precisa el papel de la educación física en la Escuela Activa como una de sus realizaciones más concretas a la hora de los balances sobre sus aportes a la educación colombiana. Este planteamiento propone una nueva mirada sobre la Educación Física que supere los estudios descriptivos y parciales. Entre instrucción y educación y la escuela se constituye en la tabla salvadora de la cuestión social.

\section{La perspectiva del cuerpo}

Uno de los problemas de investigación en la actualidad es el de la interpretación de la historia de la educación física en relación con el cuerpo. Ello produce nuevos temas y métodos de análisis, al interior de la educación física, de la historia de la educación y de otras disciplinas, en particular la antropología. En esta línea se destacan los trabajos recientes de Claudia Ximena Herrera y de Zandra Pedraza.

Desde la educación física, Claudia Ximena Herrera, en su tesis de maestría Las prácticas corporales y la educación física en la escuela primaria en Colombia entre 1870 y $1913^{103}$ expone la necesidad de descubrir "los lugares que el cuerpo y en particular el del niño, ha ocupado en la pedagogía de finales del siglo XIX y comienzos del XX". Para ello caracteriza la política educativa del período investigado a partir del decreto orgánico de la instrucción pública de 1870, y en particular el papel desempeñado por la Iglesia Católica y su disputa con el Estado para el control de la educación. Analiza la pedagogía católica y la ubicación del cuerpo y su relación con la moral. Señala la aparición del cuerpo infantil y su forma de disciplinarlo a partir del desarrollo armónico de las facultades, diferenciadas para niños y niñas. Desarrolla la discusión dada por la pedagogía católica al sensualismo de Bentham, y la imposición de la primera a través de las virtudes cristianas. En su exposición va planteando la transformación de la pedagogía de una moral católica a una moral médicobiológica que tenía en la higiene un medio de formación del cuerpo y del alma.

Presenta la educación física como una nueva tecnología educativa que cumple su papel a partir del precepto de Juvenal, de mente sana en cuerpo sano, transformado de sus principios originales, sobre los cuales se orienta una estrategia contra la degeneración de la raza. Hace un recorrido sobre diferentes aspectos de la educación física en cuanto sus orígenes en las escuelas gimnásticas europeas, los métodos, los medios y la formación de los institutores.

La escuela se caracteriza como el lugar privilegiado para la formación de la infancia en la cual las prácticas corporales se utilizan para educar moral y físicamente. A comienzos del siglo

el saber de la educación física que se venía posicionando como un ramo de la instrucción tan importante como los otros fue objeto de atención especial por parte del saber de la medicina desde la fisiología y la higiene justificando su acción desde la urgencia de salvar la raza que venía en proceso de degeneramiento. . .así como el discurso moral del siglo XIX con sus

${ }^{103}$ Claudia Ximena Herrera, Las prácticas corporales y la educación física en la escuela primaria en Colombia entre 1870 y 1913. Bogotá. Tesis de grado, Maestría en Historia de la Educación y la Pedagogía, Universidad Pedagógica Nacional, 1999. 
prácticas religiosas contenido en los manuales, sufrió un desplazamiento hacia prácticas médicas e higiénicas en el siglo XX (por el año 1913 aproximadamente); y con ellas la intensificación del sentido de utilidad y responsabilidad frente a la patria se inclinó en el rendimiento en el trabajo; también el saber de la educación física entrado el siglo XX reducirá su acción hacia los aspectos técnicos y médicos (pág. 242).

En el primer semestre de 1999 se publicó el texto de la antropóloga Zandra Pedraza Gómez de la Universidad de Los Andes titulado En cuerpo y alma: visiones del progreso y la felicidad ${ }^{104}$, dedicado al estudio de los ideales del cuerpo que han definido la modernidad en Colombia, elaborado a partir de los discursos, que desde los medios escritos, en particular de las cartillas de urbanidad y la revista Cromos, se difundieron entre los sectores sociales. Es una investigación amplia que abarca desde finales del siglo XIX con un especial énfasis en la primera mitad del siglo XX, con la irrupción de la modernización.

La obra "atiende con una mirada histórico antropológica a las particularidades del fenómeno de las figuraciones corporales en los discursos de la modernidad colombiana, que pueden distinguirse con alguna claridad desde la segunda mitad del siglo XX. Pretende evidenciar cómo ha sido entendido e imaginado el cuerpo, qué alcances y necesidades se le han atribuido, cómo se concibe la posibilidad de crearlo o transformarlo, y con él al ser humano"105.

La autora señala la existencia de cuatro discursos sobre el cuerpo en la modernidad colombiana: urbanidad, higiene y salud, cultura física y los discursos hiperestésicos.

Plantea la urbanidad como "la primera gran elaboración simbólica occidental en torno al comportamiento y al lenguaje corporal, y su recepción en Latinoamérica fue prolija por parte de letrados, que atentos a su minuciosa gramática corporal, destacaron las aptitudes retóricas de la urbanidad hasta hacer de ella una expresión virtuosa“106.

Describe la construcción minuciosa de los diseños de comportamientos que expresaban mecanismos de distinción a través de los cuales se estrechan privilegios, se frenan impulsos democratizantes y se controla la intimidad. Con el correr del siglo el discurso de la urbanidad se desplaza de las virtudes señoriales y morales hacia hábitos más pragmáticos y cívicocomunicativos.

El discurso de la salud y la higiene se explica desde el cuerpo como ente biológico y su paso del dominio social al de los especialistas. Por ello los discursos giran en torno a las prácticas y sus beneficios.

Sin embargo, la cientificidad que aureola el discurso impide que se lo incorpore a una tradición de la que siempre se mantiene distante, e impide también que esa tradición pueda cuestionarlo. A pesar de ser definitivo para la concreción de un cuerpo moderno, el discurso nacional de la

\footnotetext{
${ }^{104}$ Zandra Pedraza Gómez, En cuerpo y alma: visiones del progreso y la felicidad. Bogotá. Universidad de Los Andes, 1999.

${ }^{105}$ Zandra Pedraza Gómez, La cultura somática de la modernidad: historia y antropología del cuerpo en Colombia. En: Cultura, política y modernidad. CES. Universidad Nacional, Bogotá, 1999.

${ }^{106}$ Ibíd. 
salud ha hecho el menor aporte para que se configure y afirme una semántica somática que refuerce y enriquezca la tradición cultural del cuerpo ${ }^{107}$.

El texto interpreta la constitución de la higiene como propósito nacional y su desarrollo en la escuela, describe las campañas higienistas sobre nutrición, alcoholismo, paludismo, uncinariasis, sífilis, lepra y tuberculosis. Sobre la conservación de la salud se refiere a las políticas de producción y control poblacional, a los cuidados básicos y a su relación con lo moral tanto en la infancia como los hombres y las mujeres. Desde esta perspectiva se comprende que "el legado fundamental del discurso higiénico es haber incorporado el cuerpo al desarrollo de una subjetividad moderna en que toda forma de progreso pasa necesariamente por la crítica y transformación corporal"108.

El discurso de la cultura física se inicia como vástago de la higiene con el interés del fortalecimiento del organismo contra las enfermedades, la obesidad, para pasar al aprendizaje de técnicas que canalicen y empleen la energía.

Declinaron, pues, los deportes señoriales —la equitación, los paseos y bailes- para dar aliento a la precisión, la velocidad y la seguridad de la calistenia, la gimnasia rítmica, los deportes y el atletismo, nuevas modalidades que incidieron en el perfeccionamiento del ser humano estimulando su energía vital, educando la inteligencia, controlando el tiempo y los nervios.

Se toman como dimensiones del cultivo del cuerpo la extensión, a través de la popularización y la profesionalización, la intensidad por medio de bailes y prácticas corporales alternativas, y la forma, en la cual se va a enfatizar sobre el mantenimiento de las cualidades que lleven a la eterna juventud y la atracción.

El discurso de la hiperestesia se refiere a la "dimensión corporal que se dispone a ocupar los discursos sobre el significado de las prácticas que trasciendan esta dimensión material para administrar las propiedades emocionales que se originan en el cuerpo y cargarlas de sentido", se trata de "establecer un contacto inmediato entre las acciones externas del cuerpo y sus representaciones -imágenes de lo más recóndito de la esencia humana, de sus emociones, inteligencia, sentimientos, ideas y pasiones- a través de interpretaciones sensibles de las percepciones sensoriales, en una palabra, de estesias" 109

El texto plantea el desarrollo de la educación de los sentidos, el interés por la belleza y la relación entre el cuerpo y el alma, los métodos y técnicas de cuidado, el artificio.

"La alegoría del cuerpo moderno permite así formular la quimera de la moderna plenitud. En ella se conjugan las metáforas concebidas por minuciosos y diligentes discursos que comparecen en este escenario para evocar una imagen de integridad que supere la dicotomía cuerpo-alma y que, si no es realizable, sí permite en cambio imaginar y representar un ser humano en el que se diluye el abismo entre la muerte y la vida, entre la naturaleza y la cultura ${ }^{110}$.

El aporte analítico en la identificación de estos cuatro discursos sobre el cuerpo en la modernidad colombiana, abren una nueva perspectiva a la investigación sobre la

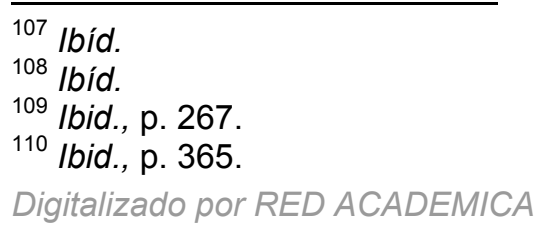


corporalidad desde enfoques transdisciplinarios, creando así las bases para múltiples relaciones con los procesos sociales, culturales, políticos y educativos que apoyan nuevos aportes al conocimiento histórico y a los factores que han intervenido en la construcción de la educación física en el país.

\section{Conclusiones}

Al realizar un balance de la producción historiográfica sobre la educación física, se aprecia un creciente interés por la exploración de diferentes temas, una cualificación en los enfoques y metodologías de la investigación y un vuelco hacia lo social y cultural. La historia descriptiva y anecdótica parece tender hacia un cambio por una historia de mayor análisis y búsqueda de significaciones. De igual manera se percibe la aproximación al campo histórico de la educación física de profesionales que provienen de diferentes áreas como profesores de educación física, sociólogos, periodistas, antropólogos, lo cual plantea una apertura hacia trabajos transdisciplinarios que tienen en el cuerpo su objeto privilegiado.

Llama la atención la importancia que se asigna a la educación física en la investigación pedagógica y antropológica que demuestra el entusiasmo por asumir temas que requieren el establecimiento de relaciones con otros campos de la cultura y las ciencias sociales.

En los distintos trabajos se percibe un fuerte proceso de discusión y profundización sobre el objeto de la educación física en el que se plantean discursos que provienen de la medicina y la psicología, con un cambio de énfasis hacia los discursos pedagógicos de formación integral y de destrezas corporales, en especial gimnásticas y deportivas. Se pasa del discurso de la salud, la higiene y el fortalecimiento racial hacia el de los procedimientos de actividades pedagógicas y sus efectos formativos en la dimensión moral y cívica de la personalidad, fortaleciendo así un enfoque activista en desmedro de una cualificación conceptual que reconozca la diversidad de campos y temas de la corporalidad y su problemática.

Con el avance de la investigación histórica en diferentes campos, con las nuevas perspectivas de trabajo compartido de los historiadores y el propio fortalecimiento de la historia de la educación, la investigación sobre educación física tiende a una nueva etapa. Se exploran metodologías que permitan indagar las relaciones con lo social y cultural desde el interior de las prácticas mismas e ir consolidando un campo de investigación que asuma la problemática de la corporalidad en la dinámica de la cultura.

En la diversidad de temas de investigación, que se mencionan en algunos casos y en otros se avanza en su desarrollo, se destaca el papel desempeñado por la educación física en la pedagogía activa, el deporte, el uso del tiempo libre, el juego, la formación profesional, la legislación, la organización institucional y social. Pero el tema que cobra mayor importancia y representa un vuelco para la interpretación de la educación física es el referido a la corporalidad. Al asumir el problema del cuerpo como objeto de investigación histórica de la educación física se produce un cambio conceptual, metodológico y de perspectivas del conocimiento que potencian trabajos desde distintos enfoques educativos y sociales.

Sobre el papel de la educación física en los primeros cincuenta años del siglo, a partir de los trabajos consultados, se observa que si bien la educación física ya se planteaba en el siglo XIX como una actividad de los programas escolares, es en el siglo XX donde logra su 
reconocimiento y toma de posición tanto en la escuela como en la institucionalidad del Estado y la sociedad a través de la Comisión Nacional de Educación Física, de las direcciones departamentales, del Instituto Nacional de Educación Física para atender la formación de educadores especializados, así como la creación de diferentes tipos de organización deportiva y de clubes sociales.

El reconocimiento y posición social tiene sus limitaciones dadas por la cobertura escolar, aunque su práctica se amplía por las diferentes actividades y tipos de organización de iniciativa social y por la motivación de los medios de comunicación que logran ampliar los niveles de divulgación y convocatoria a la participación social, en unas oportunidades de manera directa y en otras como espectadores.

El proceso de creación de prácticas, instituciones y conceptos y el reconocimiento de la educación física como un área de interés social, abre la posibilidad de la profundización desde la perspectiva de la cultura política, para ubicar el marco político y cultural al cual corresponde este interés, los conceptos que se pusieron en juego, las prácticas que se cambiaron o se crearon y el impacto en la sociedad colombiana en el proceso de modernización. 